\title{
Phosphorylcholine-Primed Dendritic Cells Aggravate the Development of Atherosclerosis in $\mathrm{ApoE}^{-/-}$Mice
}

\author{
Qian Dong, PhD; Jian Yu, BSc; Yan Ding, BSc; Qing-Wei Ji, PhD; \\ Rui-Rui Zhu, PhD; Yu-Zhen Wei, PhD; Wen-Bing Xu, BSc; Yu-Cheng Zhong, PhD; \\ Zheng-Feng Zhu, PhD; Kai Meng, PhD; Yu-Dong Peng, PhD; Hai-Tao Sun, PhD; \\ Yue Wang, BSc; Cheng-Liang Pan, BSc; Qiu-Tang Zeng, PhD; Kun-Wu Yu, PhD
}

\begin{abstract}
Background: Atherosclerosis is an inflammatory disease involving activation of adaptive and innate immune responses to antigens, including oxidized low-density lipoprotein (oxLDL) and phosphorylcholine (PC). Dendritic cells (DCs), which are antigen-presenting cells that activate $\mathrm{T}$ cells, are present in atherosclerotic lesions and are activated in immune organs. However, the mechanism by which PC promotes atherosclerosis is unclear.
\end{abstract}

\begin{abstract}
Methods and Results: To evaluate whether PC promotes atherosclerosis via DCs, $2 \times 10^{5}$ DCs activated by PC-keyhole limpet hemocyanin (DCs+PC-KLH) were injected into $\mathrm{ApoE}^{-/-}$mice and the features of the plaques and the effects of the DCs on cellular and humoral immunity against PC-KLH were determined. Mice injected with DCs+PC-KLH had significantly larger atherosclerotic lesions than controls, with increased inflammation in the lesions and plaque instability. Furthermore, DCs+PC-KLH were characterized using flow cytometry after coculture of bone marrow-derived DCs and naïve T cells. DCs+PC-KLH showed an inflammatory phenotype, with increased CD86, CD40, and major histocompatibility complex Class II molecules (MHC-II), which promoted PC-specific T helper (Th) 1 and Th17 cell differentiation in vivo and in vitro. Moreover, 2 weeks after the administration of DCs+PC-KLH to mice, these mice produced PC- and oxLDL-specific IgG2a, compared with no production in the controls.
\end{abstract}

Conclusions: These findings suggest that DCs presenting PC promote specific immunity to PC, increase lesion inflammation, and accelerate atherosclerosis, which may explain how PC promotes atherosclerosis.

Key Words: Atherosclerosis; Cellular immunity; Dendritic cells; Humoral immunity; Phosphorylcholine

I $\mathrm{n}$ recent years, considerable research has focused on the immune inflammatory response associated with atherosclerosis and its clinical manifestations. It is now widely recognized that chronic inflammation caused by $\mathrm{T}$ cell-mediated pathogenic responses plays an important role in atherogenesis. ${ }^{1}$ Recently, the pathogenic function of $\mathrm{T}$ helper (Th) 1 cells in atherosclerosis has been convincingly demonstrated in murine systems. ${ }^{2,3}$ There is additional evidence supporting an important role for Th17 cells and interleukin (IL)-17 in atherogenesis. ${ }^{4}$ In contrast, other studies have demonstrated an atheroprotective effect for naturally occurring $\mathrm{CD} 4{ }^{+} \mathrm{CD} 25^{+} \mathrm{Foxp} 3^{+}$regulatory $\mathrm{T}$ cells (nTregs). ${ }^{5}$ In addition, B1a lymphocytes are atheroprotective by secreting natural IgM, whereas conventional B2 cells aggravate atherosclerosis by secreting IgG.6,7 Meanwhile, dendritic cells (DCs), as antigen-presenting cells (APCs), have different roles in the progression of atherosclerosis through their regulation of T and B cell responses. ${ }^{8}$

Recently, oxidized low-density lipoprotein (oxLDL) was identified as a major autoantigen for the immune response associated with atherosclerosis. ${ }^{1}$ oxLDL contains a variety of oxidation-specific neoepitopes on both its lipid and protein moieties, including phosphorylcholine (PC) and apolipoprotein (Apo) B100. ${ }^{9}$ Hjerpe et al found that adoptive transfer of oxLDL-treated DCs significantly accelerated atherosclerosis in $\mathrm{ApoE}^{-/-}$mice. ${ }^{10}$ In contrast, immunization with modified and native low-density lipoprotein (LDL) injected subcutaneously, as well as the injection of

Received November 10, 2020; accepted November 11, 2020; J-STAGE Advance Publication released online January 16, 2021 Time for primary review: 1 day

Department of Cardiology, Union Hospital, Tongji Medical College, Huazhong University of Science and Technology, Wuhan (Q.D., J.Y., Y.D., R.-R.Z., W.-B.X., Y.-C.Z., Z.-F.Z., K.M., Y.-D.P., H.-T.S., Y.W., C.-L.P., Q.-T.Z., K.-W.Y.); Department of Cardiology, the People's Hospital of Guangxi Zhuang Autonomous Region, Nanning (Q.-W.J.); and Department of Cardiology, the First Affiliated Hospital of Zhengzhou University, Zhengzhou (Y.-Z.W.), China

The first four authors contributed equally to this work (Q.D., J.Y., Y.D., Q.-W.J.).

Mailing address: Qiu-Tang Zeng, PhD, and Kun-Wu Yu, PhD, Department of Cardiology, Union Hospital, Tongji Medical College, Huazhong University of Science and Technology, 1277 Jie-Fang Avenue, Wuhan City, Hubei 430022, China. E-mail: zengqt139@sina.com (Q.-T.Z.); bushyukunwu@126.com (K.-W.Y.)

All rights are reserved to the Japanese Circulation Society. For permissions, please e-mail: cr@j-circ.or.jp

ISSN-2434-0790 
antibodies against ApoB100 peptide sequences, reduced the progression of atherosclerosis. ${ }^{11,12}$ These studies demonstrate that autoimmune responses against oxLDL and ApoB100 play an important role in atherosclerosis, and that the depletion of these molecules could protect against plaque development.

PC, another component of oxLDL, is also a component of multiple prokaryotic organisms, including Streptococcus pneumoniae. Indeed, Binder et al demonstrated that many autoantibodies to oxLDL share complete genetic and structural identity with antibodies from the classic anti-PC $\mathrm{B}$ cell clone T15, which protects against common infectious pathogens, including pneumonia. ${ }^{13}$ Furthermore, pneumococcal immunization decreased the extent of atherosclerosis by producing oxLDL and PC antibodies, which indicates molecular mimicry between epitopes of PC and $S$. pneumoniae. ${ }^{13}$ Caligiuri et al have verified that $\mathrm{PC}$-targeting immunization directly reduces atherosclerosis by inducing PC-specific IgM. ${ }^{14}$ However, how PC activates the immune response and induces an autoimmune reaction in atherosclerosis remains unclear.

To investigate the role of DCs in the PC-induced immune response, we transferred DCs pulsed with $\mathrm{PC}$ to $\mathrm{ApoE}^{-/-}$ mice. This transfer induced specific humoral and cellular immune responses in vivo and significantly increased lesion development.

\section{Methods}

\section{Reagents and Antibodies}

The cell culture medium for DCs and splenocytes was RPMI 1640 (Gibco-BRL, Grand Island, NY, USA) supplemented with $10 \%$ fetal calf serum (FCS; Gibco-BRL) and $100 \mathrm{U} / \mathrm{mL}$ streptomycin-penicillin. Granulocytemacrophage colony stimulating factor (GM-CSF; Lot no. 050755-1), IL-4 (Lot no.1106CY49), and IL-2 (Lot no.0608108) were obtained from Peprotech (Rocky Hill, NJ, USA). PC-keyhole limpet hemocyanin (PC-KLH) and keyhole limpet hemocyanin $(\mathrm{KLH})$ were obtained from Biosearch Technologies (Novato, CA, USA). The purified anti-CD4 antibody (Ab; clone RM4-5) was from BD Systems (Franklin, NJ, USA). Fluorescein isothiocyanate (FITC)-conjugated anti-CD11c (Clone N418), phycoerythrin (PE)-conjugated anti-CD86 (Clone PO3.1), anti-major histocompatibility complex Class II (MHC-II)-APC (Clone HIS19), anti-CD40-PE (Clone 5C3), anti-CD45-FITC (Clone HI30), anti-CD19-APC (Clone HIB19), anti-CD4FITC (Clone GK1.5), anti-CD25-APC (Clone PC61.5), anti-Foxp3-PE (Clone FJK-165), anti-interferon (IFN)$\gamma$-PE (Clone XMG1.2), anti-IL-17A-PE (Clone eBio17B7), anti-Foxp3-biotin (Clone FJK-16s), and anti-CD11c-biotin (Clone N418) Abs were obtained from eBioscience (San Diego, CA, USA). Anti-CD68 Ab was obtained from Millipore and anti-smooth muscle actin (SMA) Ab (Lot no. BM0002) was obtained from Boster (Wuhan, China). Control rat IgG was obtained from ThermoFisher Scientific (Rockford, IL, USA).

\section{Animals}

C57BL/6 mice and ApoE ${ }^{-1-}$ mice from a C57BL/6 background (Jackson Laboratory, Bar Harbor, ME, USA) were bred and maintained in the Animal Center of Beijing University. The mice were kept in-house in a specific pathogen-free facility (Tongji Medical College, Wuhan, China) and were fed a normal chow diet or a Western-style diet containing $0.15 \%$ cholesterol and $21 \%$ fat. The mice were 6 weeks old at the start of the experiment. Diet and water were provided ad libitum. All experiments were performed in compliance with the guidelines of the Care and Use of Laboratory Animals (Science and Technology Department of Hubei Province, China, 2005. http://kjt.hubei. gov.cn/kjdt/ztzl/fzxczl/xfyf/dffg/202008/t20200826_2837541. shtml).

\section{Generation of Bone Marrow-Derived DCs (BM-DCs)}

BM-DCs were generated with GM-CSF and IL-4 as described previously. ${ }^{15}$ Briefly, bone marrow was isolated from C57BL/6 mice. Bone marrow cells were depleted of red blood cells and were cultured with RPMI 1640 for 6 days in tissue culture plates at $37^{\circ} \mathrm{C}$ under $5.0 \% \mathrm{CO}_{2}$. The RPMI 1640 culture medium was supplemented with $10 \%$ FCS, $100 \mathrm{U} / \mathrm{mL}$ penicillin, $100 \mathrm{U} / \mathrm{mL}$ streptomycin, $10 \mathrm{ng} / \mathrm{mL}$ GM-CSF, and $10 \mathrm{ng} / \mathrm{mL}$ IL-4. DCs were purified from the differentiated bone marrow cells using a CD11c magnetic cell-sorting kit (Miltenyi Biotec, Gladbach, Germany) according to the manufacturer's instructions. After purification, DCs were stimulated with KLH (DCs+KLH) or exposed to $50 \mu \mathrm{g} / \mathrm{mL}$ PC-KLH (DCs+PC-KLH) in RPMI 1640. After $48 \mathrm{~h}$, the DCs and supernatants were collected for further experimentation.

\section{T Cell and BM-DCs Coculture In Vitro}

$\mathrm{CD}^{+} \mathrm{T}$ cells were purified from splenocytes of $\mathrm{ApoE}^{-/-}$ mice using the Naïve $\mathrm{CD}^{+}{ }^{+} \mathrm{T}$ Cell Isolation Kit, mouse (Miltenyi Biotec) according to the manufacturer's instructions. $\mathrm{CD} 4{ }^{+} \mathrm{CD} 25^{+}$regulatory $\mathrm{T}$ (Treg) and $\mathrm{CD} 4{ }^{+} \mathrm{CD} 25^{-}$ $\mathrm{T}$ cells were isolated from all $\mathrm{CD}^{+} \mathrm{T}$ cells using a $\mathrm{CD} 4^{+} \mathrm{CD} 25^{+}$Regulatory $\mathrm{T}$ Cell Isolation Kit (Miltenyi Biotec). Fluorescence-activated cell sorting (FACS) analysis indictated that the purity of each population was $>93 \%$. Using 24-well plates, $8 \times 10^{5} \mathrm{CD} 4^{+} \mathrm{CD} 25^{-} \mathrm{T}$ cells were cultured either alone or with $2 \times 10^{5} \mathrm{DCs}+\mathrm{KLH}$ or DCs+PC-KLH in RPMI 1640 in the presence of $2 \mu \mathrm{g} / \mathrm{mL}$ anti-CD3 $\mathrm{Ab}$ and $4 \mathrm{ng} / \mathrm{mL}$ IL-2 for $72 \mathrm{~h}$. The cells were pulsed with $1 \mu \mathrm{Ci}\left[{ }^{3} \mathrm{H}\right]$-thymidine/well during the last $18 \mathrm{~h}$ and the radioactivity in the cells was assayed at the end of the culture period. The supernatants were also collected at the end of the 72-h incubation period for cytokine quantification using ELISA (eBioscience).

\section{Splenocyte Proliferation Assay}

Spleens from ApoE ${ }^{-1-}$ mice in the no DCs, DCs+KLH, and DCs+PC-KLH groups ( $n=3$ per group) were dissected and passed through a Falcon $70-\mu \mathrm{m}$ cell strainer. Erythrocytes were eliminated by incubating the cells with erythrocyte lysis buffer $\left(0.15 \mathrm{~mol} / \mathrm{L} \mathrm{NH} 4 \mathrm{Cl}, 10 \mathrm{mmol} / \mathrm{L} \mathrm{NaHCO}_{3}\right.$, $0.1 \mathrm{mmol} / \mathrm{L}$ EDTA, pH 7.3). Splenocytes were cultured for $72 \mathrm{~h}$ in triplicate at a density of $2 \times 10^{5}$ cells per well in 96-well round-bottomed plates in the presence or absence of different concentrations of PC-KLH. RPMI 1640 (with L-Glutamine $2 \mathrm{mmoL}, 10 \% \mathrm{FCS}, 100 \mathrm{U} / \mathrm{mL}$ penicillin, and $100 \mu \mathrm{g} / \mathrm{mL}$ streptomycin; all from BioWhittaker Europe) was used as the culture medium. Cultures were pulsed for an additional $18 \mathrm{~h}$ with $\left[{ }^{3} \mathrm{H}\right]$-thymidine $(1 \mu \mathrm{Ci} /$ well, specific activity $24 \mathrm{Ci} / \mathrm{mmol}$; Amersham Biosciences). The amount of $\left[{ }^{3} \mathrm{H}\right]$-thymidine incorporated was measured using a liquid scintillation counter (TRI-CARB 2900R; Perkin-Elmer, Norwalk, CT, USA). At the end of the culture period, supernatants were collected for cytokine quantification using ELISA (eBioscience). 


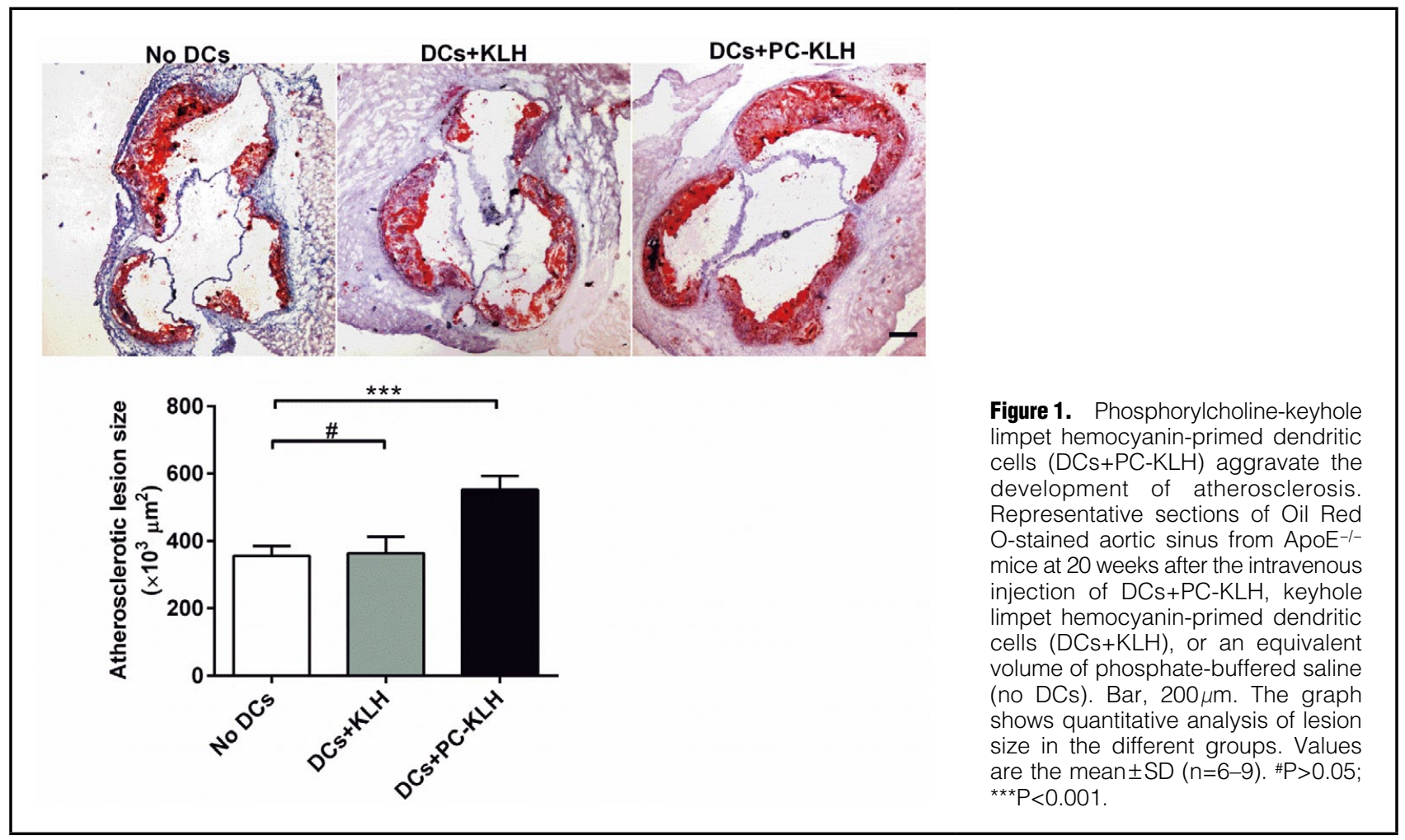

\section{Animal Groups}

In the DC transfer experiments, 6-week-old male $\mathrm{ApoE}^{-/-}$ mice were injected intravenously with $2 \times 10^{5} \mathrm{DCs}+\mathrm{KLH}$ or DCs+PC-KLH (i.e., $2 \times 10^{5}$ cells/mouse) or an equivalent volume of phosphate-buffered saline (PBS) alone (the no DCs group) once every 3 weeks until week 12 . Five days after the first injection of DCs or PBS, mice were administered a Western-style diet for 12 weeks. Each group contained 6-9 mice.

\section{Cytokine and Antibody ELISA}

Supernatants of the cultured DCs and splenocytes and no DCs DCs+KLH DCs+PC-KLH after 12 weeks were collected for determination of IL-4, IFN- $\gamma$, and IL-17a using a commercially available ELISA (eBioscience) according to the manufacturer's instructions. To quantify oxLDL- or PC-specific antibodies, 96 well microplates were coated with $100 \mu \mathrm{g} / \mathrm{mL}$ oxLDL or PC, washed wish wash buffer $(0.05 \%$ tween 20 in PBS, PH 7.2-7.4), and blocked wish Reagent diluent (1\%BSA in PBS, PH 7.2-7.4, $0.2 \mu \mathrm{m}$ filtered). Then, plasma harvested from mice was added at an optimized dilution of 1:50 and specific antibodies to detect IgG1, IgG2a, and IgM (BD Biosciences) were added. Optical density (OD) was read at $450 \mathrm{~nm}$.

\section{Flow Cytometry}

Two weeks after the last administration of DCs, monocytes were isolated from the spleen using Ficoll-Paque Plus and erythrocyte lysis buffer to remove the erythrocytes. For the detection of $\mathrm{CD} 45^{+} \mathrm{CD} 19^{+} \mathrm{B}$ cells, the cells were first stained with anti-CD45 Ab and anti-CD19 Ab. For detection of nTregs, cells were first stained with anti-CD4-FITC Ab (R\&D Systems, Minneapolis, MN) and anti-CD25-PE Ab (R\&D Systems), fixed and permeabilized according to the manufacturer's instructions (eBioscience) and then stained with anti-Foxp3-APC Ab (eBioscience). For analysis of Th1 $\left(\mathrm{CD}^{+}{ }^{+} \mathrm{IFN}-\gamma^{+}\right)$and Th17 (CD4 $\left.{ }^{+} \mathrm{IL}-17^{+}\right)$cells, monocytes were suspended at a density of $2 \times 10^{6}$ cells $/ \mathrm{mL}$ in complete culture medium. Then, $1 \mathrm{~mL}$ of the cell suspension was transferred to each well of a 24-well plate. Cultures were stimulated with phorbol myristate acetate $(20 \mathrm{ng} / \mathrm{mL})$ plus ionomycin $(1 \mu \mathrm{g} / \mathrm{mL}$; Alexis Biochemicals, San Diego, CA, USA) for $4 \mathrm{~h}$ in the presence of $2 \mu \mathrm{mol} / \mathrm{mL}$ monensin (Alexis Biochemicals) in an incubator at $37^{\circ} \mathrm{C}$ under $5 \%$ $\mathrm{CO}_{2}$. After $4 \mathrm{~h}$ culture, the monocytes were collected for staining refer to the R\&D instruction manual. Fixation and permeabilization were necessary before staining with IFN- $\gamma$ or IL-17 Ab. Isotype controls were used to enable correct compensation and to confirm antibody specificity.

To characterize the cultured DCs, purified CD11c cells were stained with CD86, CD40, or MHC-II for $30 \mathrm{~min}$. Flow cytometric acquisition was performed using a FACSCalibur (BD Immunocytometry Systems) and all analyses were performed using Flowjo software (Treestar Inc., Ashland, OR, USA).

\section{Body Weight and Lipids}

At the end of experiment, the weight of each mouse was recorded. Blood samples were collected, allowed to clot at room temperature, and the plasma was then isolated by centrifugation at $1,200 \mathrm{~g}$ for $10 \mathrm{~min}$ at $25^{\circ} \mathrm{C}$. Plasma concentrations of total cholesterol, oxLDL, and triglycerides were measured by enzymatic assay and determined using an autoanalyzer (Hitachi 917).

\section{Atherosclerotic Lesion Analysis}

Atherosclerosis lesions were quantified in the aortic sinus and descending thoracic aorta, as described previously. ${ }^{\mathbf{1 6}}$ 

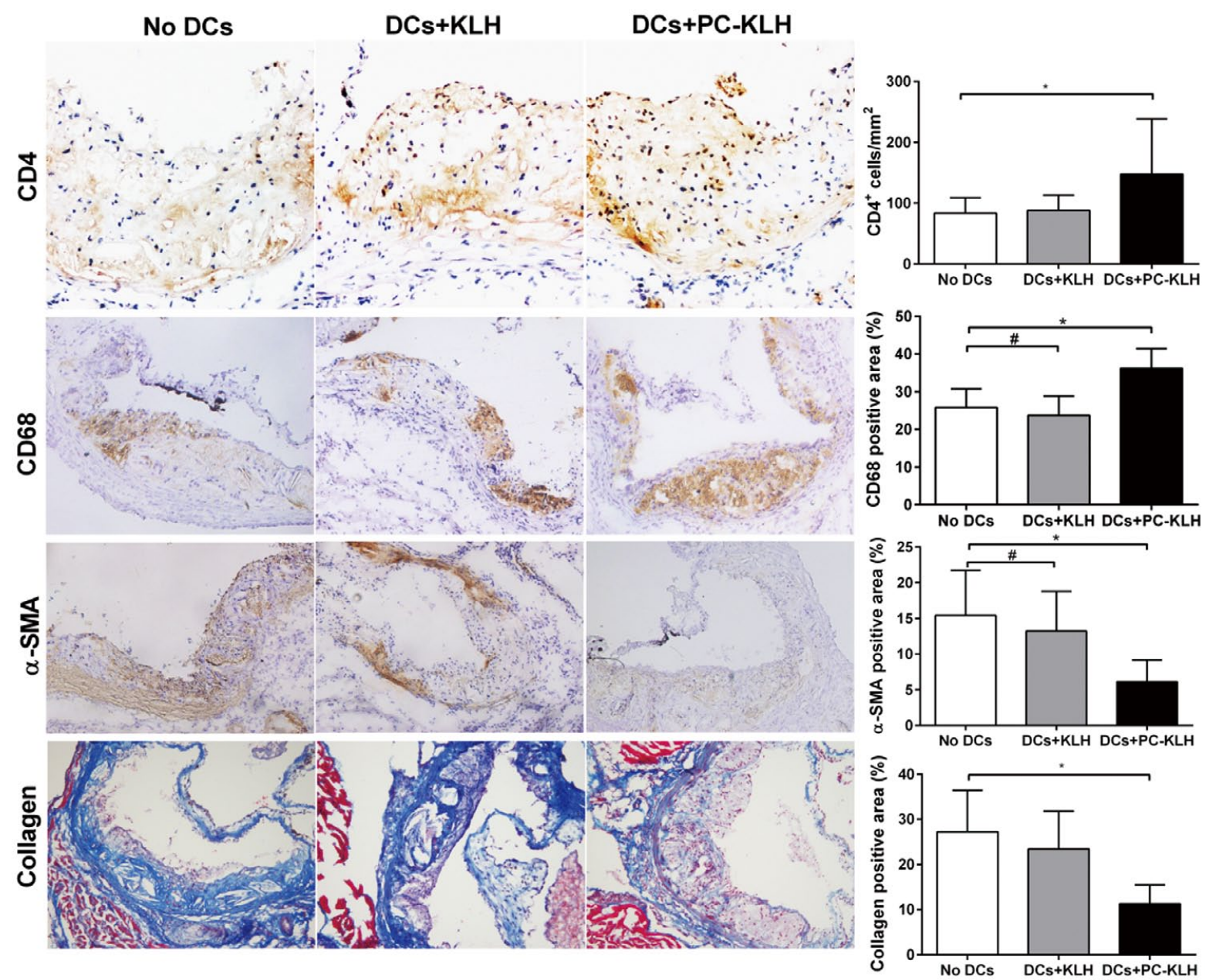

Figure 2. Effects of phosphorylcholine-keyhole limpet hemocyanin-primed dendritic cells (DCs+PC-KLH) on plaque phenotype. Images show representative sections of the aortic sinus stained with antibodies specific for CD4 (CD4+ T lymphocytes), CD68 (macrophages), and $a$-smooth muscle actin (SMA), and Masson staining for collagen, from ApoE-l- mice at 20 weeks after the intravenous injection of DCs+PC-KLH, keyhole limpet hemocyanin-primed dendritic cells (DCs+KLH), or an equivalent volume of phosphate-buffered saline (no DCs). Bar, $200 \mu \mathrm{m}$. The graphs show quantitative analysis of positively stained cells in each group. Values are the mean $\pm S D(n=5-6)$. \#P>0.05; ${ }^{*} P<0.05$.

Briefly, the hearts after 12 weeks including the aortic roots were prepared, which were remove from left auricle to right auricle and sections were fixed in $4 \%$ formaldehyde, processed, and embedded in oxytetracycline (OTC) compound. Sections $(5-7 \mu \mathrm{m})$ were cut at $35-\mu \mathrm{m}$ intervals starting from the 3 -valve cusp of the aortic sinus. In addition, the descending thoracic aorta was dissected and fixed, opened longitudinally, and pinned onto black wax plates. All specimens were stained with Oil Red O (ORO) and hematoxylin. Plaque area was measured in each mouse using Image-Pro Plus 6.0 (Media Cybernetics, Silver Spring, MD, USA).

For immunohistochemical analysis, 5- to 7- $\mu \mathrm{m}$ serial cryostat sections of the aortic sinus adjacent to the OROstained sections and heart tissue were prepared. Sections were stained using the following molecule-specific antibodies: purified anti-CD68 Ab $(1: 200)$ for monocytes and macrophages, purified anti- $\alpha$-SMA Ab $(1: 200)$ for smooth muscle cells (SMCs), and purified anti-CD4 Ab $(1: 50)$ for T cells.
For purified $\mathrm{Ab}$, staining was visualized using biotinylated secondary antibodies. For biotinylated Ab, staining was visualized using streptavidinylated secondary antibodies and detected with the Avidin-Biotin Complex/Diaminobenzidine $(\mathrm{ABC} / \mathrm{DAB})$ system. Masson trichrome staining was used to detect collagen. Macrophages, SMCs, and collagen were quantified by determining the positively stained area as a percentage of the total plaque for each marker. $\mathrm{CD} 4^{+} \mathrm{T}$ cells were assessed by counting the number of stained positive cells per square millimeter in the plaque area.

\section{Statistical Analysis}

Unless indicated otherwise, results are expressed as the mean \pm SD. For normally distributed data with equal group variances, comparisons were made between 2 groups using Student's t-test. For data that were not normally distributed or if group variances were unequal, comparisons were made using the Mann-Whitney rank-sum test. One-way analysis 


\begin{tabular}{|lcccc|}
\multicolumn{5}{l}{ Table. BW and TC, oxLDL, and TG Plasma Concentrations in Mice in the Different Experimental Groups } \\
No DCs & BW (g) & TC ( $\mathbf{m m o l} / \mathbf{L})$ & TG $(\mathbf{m m o l} / \mathbf{L})$ & oxLDL $(\mathbf{n m o l} / \mathbf{m L})$ \\
DCs + KLH & $29.78 \pm 1.61$ & $17.04 \pm 1.88$ & $1.60 \pm 0.17$ & $1,050 \pm 139$ \\
DCs + PC-KLH & $29.75 \pm 1.50$ & $16.65 \pm 1.94$ & $1.64 \pm 0.14$ & $1,054 \pm 148$ \\
\hline
\end{tabular}

Data are presented as the mean $\pm S D$ ( $n=6$ in each group). Mice ( 6 weeks old) were injected intravenously with $2 \times 10^{5}$ dendritic cells (DCs) cultured with keyhole limpet hemocyanin (DCs+KLH), $2 \times 10^{5} \mathrm{DCs}$ cultured with phosphorylcholinekeyhole limpet hemocyanin (DCs+PC-KLH), or an equivalent volume of phosphate-buffered saline (no DCs). All determinations were made after 12 weeks. BW, body weight; oxLDL, oxidized low-density lipoprotein; TC, total cholesterol; TG, triglyceride.
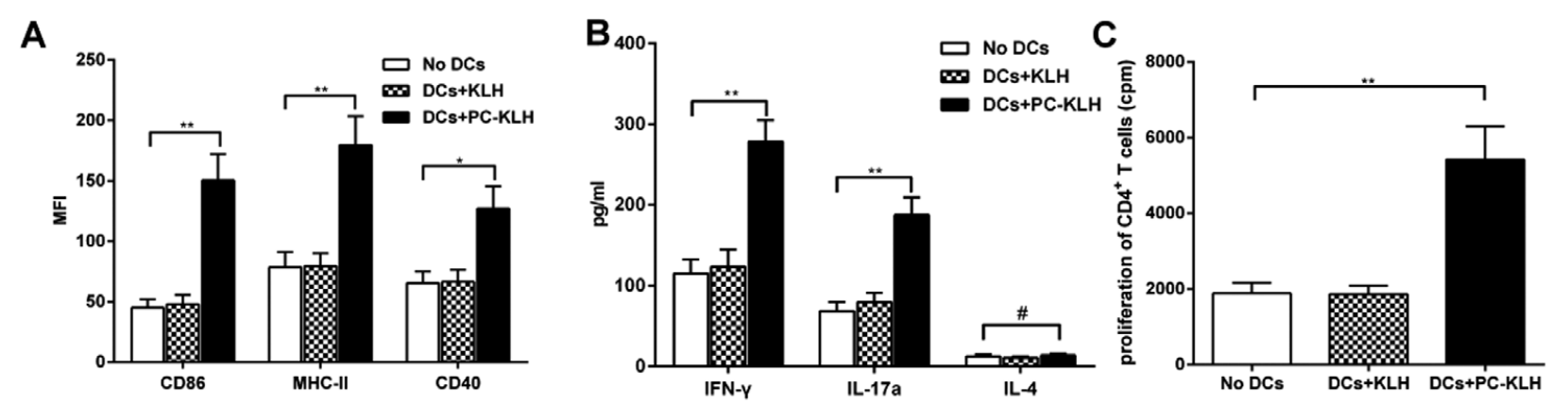

Figure 3. Characterization of phosphorylcholine-keyhole limpet hemocyanin-primed dendritic cells (DCs+PC-KLH) and coculture

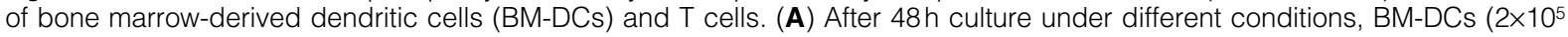
cells/well) were stained with specific antibodies against CD86, major histocompatibility complex Class II molecules (MHC-II), and CD40 and analyzed by fluorescence-activated cell sorting. Mean fluorescence intensity (MFI) was quantified. (B) CD4+ splenic T cells were cocultured with BM-DCs in a ratio of $4: 1$ for $72 \mathrm{~h}$ and the amount of interferon (IFN)- $Y$, interleukin (IL)-17a, and IL-4 released by the CD4+ $T$ cells was determined. (C) CD4+ splenic T cells were cocultured with BM-DCs in a ratio of $4: 1$ for $72 \mathrm{~h}$ in the presence of CD3 and CD28 monoclonal antibodies and the proliferation of the purified CD4+ $\mathrm{T}$ cells was measured by $\left[{ }^{3} \mathrm{H}\right]$-thymidine incorporation. Data are the mean $\pm \mathrm{SD}$ of $3-5$ independent experiments. ${ }^{*} \mathrm{P}>0.05$; ${ }^{* *} \mathrm{P}<0.01$. DCs $+\mathrm{KLH}$, cells cultured with keyhole limpet hemocyanin-primed dendritic cells; No DCs, cells cultured with an equivalent volume of phosphatebuffered saline.

of variance (ANOVA) was used for multiple comparisons between $\geq 3$ groups, followed by the Holm-Sidak test when data were normally distributed and group variances were equal. When data were not normally distributed or if group variances were unequal, the Kruskal-Wallis test followed by the Dunn test was used. All analyses were performed in GraphPad Prism 6.0. Two-sided $\mathrm{P}<0.05$ was considered significant.

\section{Results}

Effects of PC-KLH-DCs on Atherosclerosis in ApoE--- Mice To evaluate whether the observed promotion of atherosclerosis by PC was associated with DCs, mice were injected intravenously with different types of DCs (DCs + KLH or DCs + PC-KLH) or PBS as a control (no DCs). In mice injected with DCs + PC-KLH, there was a 55.2\% increase in atherosclerotic lesion size compared with that in mice in the no DCs group $\left(5.52 \pm 0.42\right.$ vs. $3.55 \pm 0.29 \times 10^{5} \mu \mathrm{m}^{2}$, respectively; $\mathrm{P}<0.01$; Figure 1). In contrast, injection of DCs + KLH did not affect area of the atherosclerotic lesion compared with the no DCs group (3.64 \pm 0.49 vs. $3.55 \pm 0.29 \times 10^{5} \mu \mathrm{m}^{2}$, respectively; P>0.05; Figure 1).

Injection of PC-KLH-DCs significantly increased CD4 ${ }^{+}$ $\mathrm{T}$ cell infiltration into the aortic sinus (Figure 2). Simulta- neously, there was an increased percentage of $\mathrm{CD}^{+} 8^{+}$ macrophages in the atherosclerotic lesions of mice in the PC-KLH-DCs group compared with the no DCs group $(\mathrm{P}<0.05$; Figure 2). Furthermore, there was a significant decrease in $\alpha$-SMA and collagen after injection of PCKLH-DCs (Figure 2). Interestingly, injection of PC-KLHDCs did not affect the body weight or total plasma cholesterol, oxLDL, and triglyceride concentrations of ApoE $^{-/-}$mice (Table).

\section{Characterization of Cultured DCs}

In a previous study we showed that oxLDL promotes the maturation and differentiation of DCs and plays an important role in the progression of atherosclerosis..$^{15}$ However, there was no evidence regarding the effect of PC on DCs. In the present study, there was distinct upregulation of mean fluorescence intensity (MFI) for the costimulatory factors CD86, MHC-II, and CD40 in PC-KLH-treated DCs (Figure 3A). In order to investigate the effects of PCKLH-DCs on T cells, T cells and BM-DCs were cocultured in vitro. In these studies, PC-KLH-DCs promoted the secretion of IFN- $\gamma$ and IL-17a, but not IL-4 (Figure 3B), and the proliferation of $\mathrm{CD}^{+} \mathrm{T}$ cells from $\mathrm{ApoE}^{-/-}$mice (Figure 3C), indicating differentiation of Th1 and Th17 cells. 

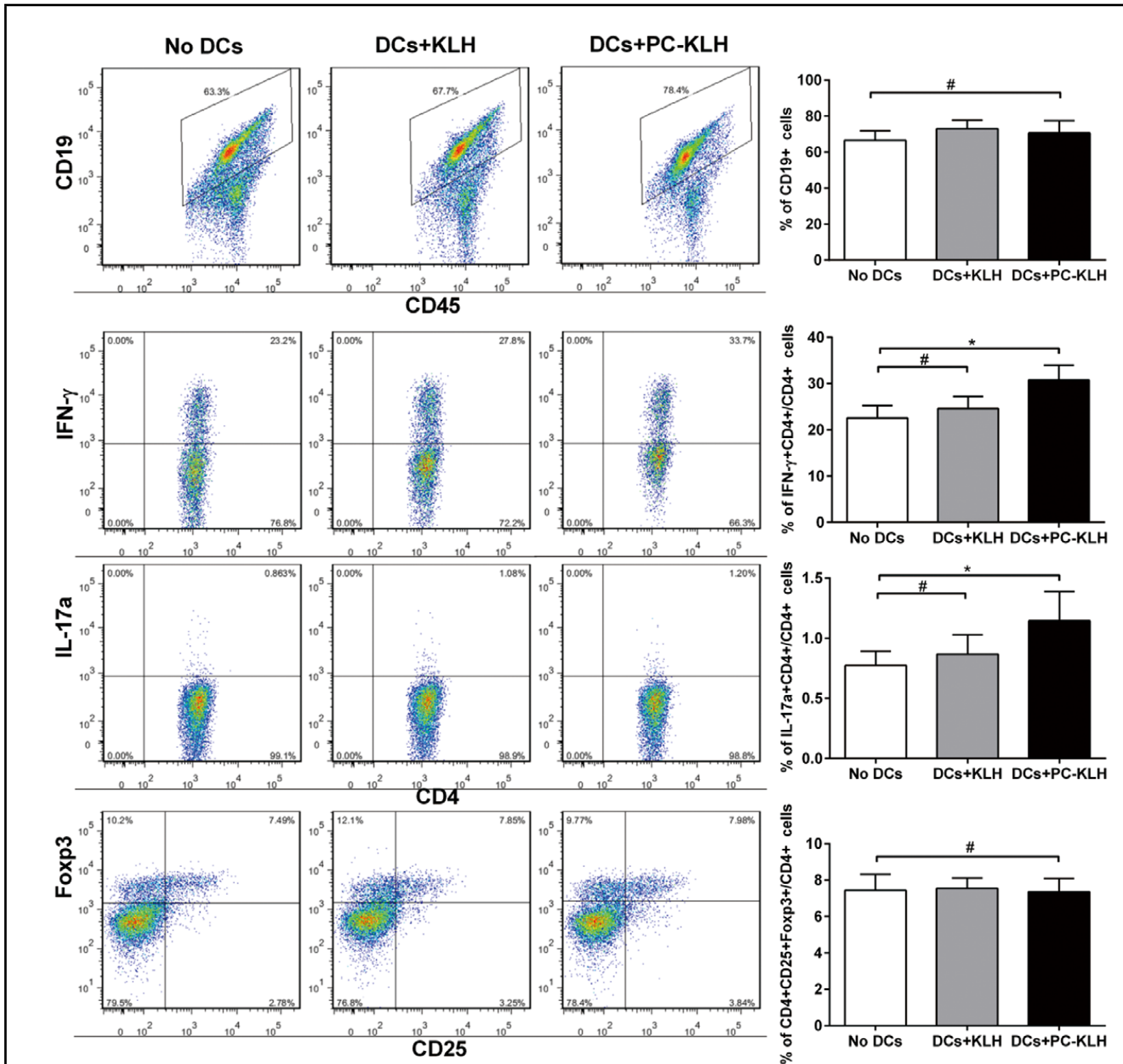

Figure 4. Effects of the injection of phosphorylcholine-keyhole limpet hemocyanin-primed dendritic cells (DCs+PC-KLH) on $B, T$ helper (Th) 1, Th17 and CD4+CD25+Foxp3+ regulatory T (Treg) cells in the spleens of ApoE-l- mice on Day 14. CD4+ T cell subsets were gated, and representative traces are shown for B, Th1, Th17, and CD4+CD25+Foxp3+ Treg cells. Numbers in the upper right quadrants indicate the percentage of these cells. Histograms show the results of statistical analysis for the mean percentages of these cells in the different groups. Data are the mean $\pm S D\left(n=6\right.$ mice per group). $\# P>0.05 ;{ }^{*} P<0.05$. DCs $+K L H$, mice injected with keyhole limpet hemocyanin-primed dendritic cells; No DCs, mice injected with an equivalent volume of phosphate-buffered saline.

\section{Effects of PC-KLH-DCs on the Induction of Th1, Th17, nTregs, and B Cells In Vivo}

To assess the functional activity of PC-KLH-DCs on splenic immune cells, we examined $\mathrm{CD}^{+} \mathrm{T}$ cell subtypes and $\mathrm{B}$ cells in the spleen of mice 2 weeks after the end of the treatment. PC-DCs treatment significantly increased the percentage of Th1 and Th17 cells, but did not affect the total number of B and nTreg cells (Figure 4).

\section{Role of Humoral Immunity in the Effects of PC-KLH-DCs on Atherosclerosis}

Atherosclerosis is related to the formation of antibodies to oxidatively modified LDL, and the levels of this antibody are associated with the progression of atherosclerosis in mice. ${ }^{17}$ The results of all the assays described above involved PC-KLH-DCs modulating cellular immunity, but we also investigated whether there was a humoral immune response to PC-KLH-DCs treatment by quantifying plasma antibody titers. Th1 cells induce IgG2a production, whereas Th2 cells facilitate IgG1 and IgE synthesis. In the present study we assessed the levels of oxLDL- and PC-specific antibodies. More PC-specific IgG2a were produced in PC-DCs-treated mice compared with controls 2 weeks after the last administration of PC-KLH-DCs (Figure 5A). Similar results 
A

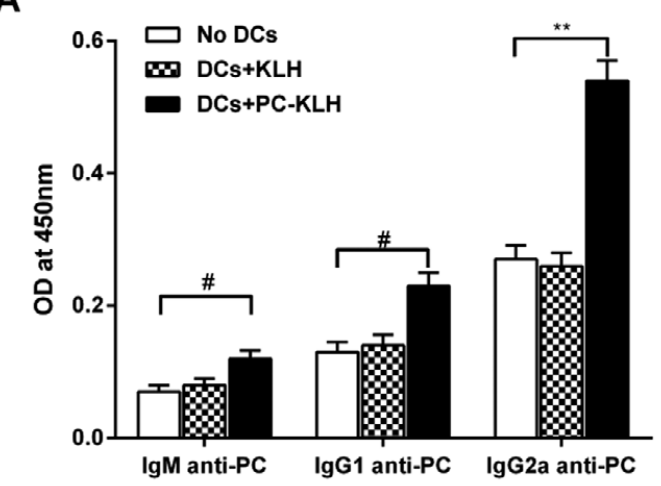

C

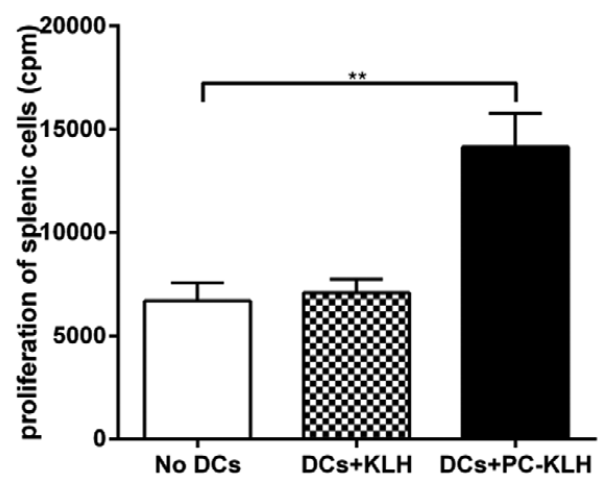

B

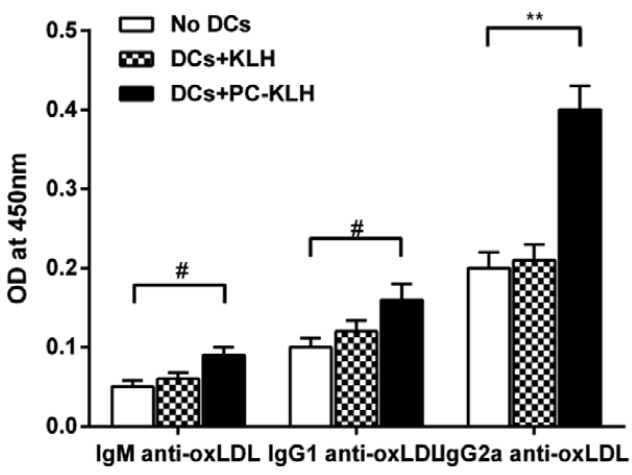

D

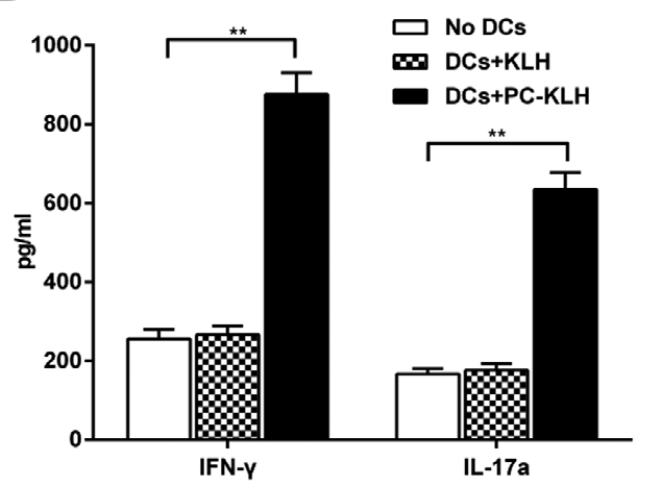

Figure 5. Induction of antigen-specific immune responses by phosphorylcholine (PC). (A,B) ELISA detection of IgM, IgG1, and IgG2a in serum recognizing PC $(\mathbf{A})$ and oxidized low-density lipoprotein (OxLDL; $\mathbf{B}$ ) in mice injected intravenously with $\mathrm{PC}$-keyhole limpet hemocyanin-primed dendritic cells (DCs+PC-KLH), keyhole limpet hemocyanin-primed dendritic cells (DCs+KLH), or an equivalent volume of phosphate-buffered saline (no DCs). OD, optical density. (C) Proliferation of splenic cells in vitro in response to $\mathrm{PC}$ antigen, as determined by $\left[{ }^{3} \mathrm{H}\right]$-thymidine uptake, in the different groups. (D) ELISA detection of interferon (IFN)- $Y$ and interleukin (IL)-17a in supernatants from cells restimulated with $P C$ antigen in vitro. Data are the mean $\pm S D(n=3-6)$. \#P>0.05; ${ }^{* *} P<0.01$.

were found for oxLDL-specific IgG2a (Figure 5B).

Antigen-specific T-cell activation was analyzed in vitro when cells from the spleen were restimulated with PC. Cells from mice injected with PC-KLH-DCs showed an approximate 2-fold increase in DNA synthesis (Figure 5C), but cells from KLH-DC-treated mice did not respond to PC antigen. In addition, PC induced the expression of IFN- $\gamma$ and IL-17a in isolated splenocytes in vitro (Figure 5D).

\section{Discussion}

This report shows that myeloid DCs are important messengers between PC and the atherogenic effect, presenting $\mathrm{PC}$ to the immune system of hypercholesterolemic mice. We found that: (1) PC-KLH-DCs, but not KLH-DCs, accelerated atherosclerosis in recipient $\mathrm{ApoE}^{-/-}$mice; (2) atherosclerotic lesions of PC-KLH-DC-treated mice exhibited an unstable plaque phenotype; and (3) PC-KLH loaded onto DCs induced Th1 and Th17 cells, and a Th1mediated humoral immune response in vitro and in vivo. Together, these data suggest that PC-KLH-DCs induce antigen-specific proatherogenic immunity that augments local and systemic inflammation and the growth of atherosclerotic lesions.
Recent evidence shows that increased DCs in atherosclerotic plaques and activated DCs in lymphoid organs in hypercholesterolemic mice contribute to local inflammation and regulate atherosclerotic development. ${ }^{18,19}$ Indeed, Miyashita et al found that PC-KLH may be dose-dependently associated with increased IL-12p40 production from splenic DCs. ${ }^{20}$ IL-12p40 is known to differentiate naïve T cells into Th1 cells and to inhibit Th2 immune responses. ${ }^{21}$ Toll-like receptor (TLR) 4 and MyD88 (MyD88 is the canonical adaptor for inflammatory signaling pathways downstream of members of the toll-like receptor (TLR) and interleukin-1 (IL-1) receptor families) signaling pathways play an important role in lipopolysaccharide (LPS)stimulated IL-12 production from DCs. ${ }^{22}$ Similar to LPS, the binding of PC to TLR4 has been demonstrated using PC-containing glycoprotein ES-62 (ES-62, which is actively secreted by the rodent filarial nematode Acanthocheilonema viteae. ES-62 has been shown to exert anti-inflammatory actions through its phosphorylcholine (PC)-containing moiety on a variety of cells of the immune system, affecting intracellular signalling pathways associated with antigen receptor- and TLR-dependent response), a secretory product of parasitic nematodes. ${ }^{23}$ These results demonstrated that PC can activate DCs to some extent.

In the present study we further investigated the effect of 
PC-KLH on DCs and T cell activation. Increased expression of costimulatory factor CD86, MHC-II, and CD40 was found on the surface of PC-KLH-DCs, indicating DC maturation. These changes may contribute to the activation of $\mathrm{T}$ cells and the formation of larger atherosclerotic lesions in this study because a CD86 deficiency in atherosclerotic mice has been reported to result in reduced early and, to some extent, advanced atherosclerotic lesion formation. ${ }^{24}$ Next, we found that PC-KLH-DCs induced the proliferation of T cells and Th1 and Th17 cell differentiation, th1 and th 17 produce IFN- $\gamma$ and IL-17. Thus, we infer that the increase in costimulatory factors on DCs induced by PC in this study led to Th17 polarization and IL-17a production. These results demonstrate that PC-KLH-DCs are inflammatory DCs. Previous research has convincingly demonstrated the pathogenic function of IFN- $\gamma$ in atherosclerosis in murine systems, as well as a $60 \%$ reduction in lesion lipid accumulation, a decrease in lesion cellularity, and a marked increase in lesion collagen content in IFN- $\gamma$ receptorknockout mice. ${ }^{2}$ Additional evidence supports an important role for Th17 cells and IL-17 in atherogenesis, in addition to promoting monocyte and macrophage recruitment into the aortic wall. ${ }^{4}$ Therefore, the increases in IL-17a and IFN- $\gamma$ may explain, in part, the aggravated and unstable plaques after the injection of PC-KLH-DCs into ApoE $\mathrm{Ap}^{-/-}$ mice.

$\mathrm{T}$ and B cells interact with each other: B cells are considered to have an important role in immunity by producing Abs with the help of Th cells, and antigen presentation to Th cells by conventional B cells can conceivably activate these $\mathrm{T}$ cells. Indeed, IgM-producing B1a lymphocytes are atheroprotective and conventional B2 cells aggravate atherosclerosis. ${ }^{6,7}$ Although the relationship among T and B cells was not completely illuminated, PC-specific IgG2a and oxLDL-specific IgG2a but not IgM were found to be increased after PC-KLH-DCs treatment. These results indicate activation of B2 cells by PC-KLH-DCs. In contrast, Caligiuri et al found that $\mathrm{PC}$ immunization via intraperitoneal injection (IP) drives specific T15-like antibodies, PCspecific IgM, that block oxLDL uptake by macrophages, reduce foam cell formation in vitro, and are atheroprotective in vivo. ${ }^{14}$ Together, this evidence demonstrates that different ways of immunization with PC activate different types of B cells, which determine a protective or pathogenic role in atherosclerosis.

Indeed, studies of autoantigen immunity in atherosclerosis have yielded complex results due to different forms of antigen presentation leading to qualitatively different immune responses. In general, subcutaneous injections of antigen with alum as the adjuvant or alum alone could protect against atherosclerosis. ${ }^{\mathbf{2 5 , 2 6}}$ In addition, intraoral or intranasal immunization with oxLDL, heat shock protein (HSP) 65, HSP60, or ApoB100 induces antigen-specific regulatory $T$ cells and reduces atherosclerosis. ${ }^{27-29}$ It may be speculated that mucosal treatment with atherosclerosisassociated antigen stimulates tolerogenic APCs, but not inflammatory APCs, and then antigen-specific $\mathrm{CD}^{+}{ }^{+} \mathrm{T}$ cells are activated within the plaque or immune organs by the development of adaptive immune cells that secrete anti-inflammatory cytokines such as IL-10 and transforming growth factor- $\beta 1$, which protect against plaque formation and promote plaque stability. These studies indicate that mucosal tolerance may be an important method for treating atherosclerosis. Similarly, the transfer of DCs loaded with oxLDL may either induce or protect against atherosclerosis depending on the phenotype of the DCs transferred. ${ }^{\mathbf{1 0}, 30}$ Treatment with immature IL-10-loaded DCs or thymic stromal lymphopoietin (TSLP) cultured DCs led to a protective effect against atherosclerosis ${ }^{15,31}$ that was associated with the development of atheroprotective CD4 ${ }^{+} \mathrm{CD} 25^{+}$ Treg cells. ${ }^{5}$ In contrast, in the present study, the administration of matured DC loaded with PC-KLH did not induce Treg cells, but promoted Th1 and Th17 cell differentiation. This may explain the opposite effects on atherogenesis between the 2 DC states.

\section{Conclusions}

In summary, PC-KLH-DCs aggravated the development of atherosclerotic lesions by promoting PC-specific Th1 and Th17 cell differentiation, and PC- and oxLDL-specific IgG2a production. Thus, the present findings explain the possible mechanism underlying the promotion of atherosclerosis by PC.

\section{Acknowledgments}

None.

\section{Sources of Funding}

This work was supported by grants from the National Natural Science Foundation of China (No. 81770273 and 81300213 to Q.-T.Z.; No. 81900400 to K.-W.Y.; No. 81560085 and 81770472 to Q.-W.J.) and the Science Foundation of Wuhan Union Hospital (No. 02.03.2018-207 and 02.03.2018-240).

\section{Disclosures}

None of the authors have any conflicts of interest to declare.

\section{IRB Information}

This study was granted an exemption from requiring ethics approval by Huazhong University of Science and Technology because it did not involve human subjects.

\section{References}

1. Hansson GK, Libby P. The immune response in atherosclerosis: A double-edged sword. Nat Rev Immunol 2006; 6: 508-519.

2. Gupta S, Pablo AM, Jiang X, Wang N, Tall AR, Schindler C. IFN-gamma potentiates atherosclerosis in ApoE knock-out mice. J Clin Invest 1997; 99: 2752-2761.

3. Zhou X, Nicoletti A, Elhage R, Hansson GK. Transfer of CD4(+) T cells aggravates atherosclerosis in immunodeficient apolipoprotein E knockout mice. Circulation 2000; 102: 29192922.

4. Smith E, Prasad KM, Butcher M, Dobrian A, Kolls JK, Ley K, et al. Blockade of interleukin-17A results in reduced atherosclerosis in apolipoprotein E-deficient mice. Circulation 2010; 121: $1746-$ 1755 .

5. Ait-Oufella H, Salomon BL, Potteaux S, Robertson AK, Gourdy $\mathrm{P}$, Zoll J, et al. Natural regulatory T cells control the development of atherosclerosis in mice. Nat Med 2006; 12: 178-180.

6. Kyaw T, Tay C, Krishnamurthi S, Kanellakis P, Agrotis A, Tipping $\mathrm{P}$, et al. B1a B lymphocytes are atheroprotective by secreting natural IgM that increases IgM deposits and reduces necrotic cores in atherosclerotic lesions. Circ Res 2011; 109: $830-840$.

7. Kyaw T, Tay C, Khan A, Dumouchel V, Cao A, To K, et al. Conventional B2 B cell depletion ameliorates whereas its adoptive transfer aggravates atherosclerosis. J Immunol 2010; 185: 44104419.

8. Zernecke A. Dendritic cells in atherosclerosis: Evidence in mice and humans. Arterioscler Thromb Vasc Biol 2015; 35: 763-770.

9. Hansson GK. Inflammation, atherosclerosis, and coronary artery disease. $N$ Engl J Med 2005; 352: 1685-1695.

10. Hjerpe C, Johansson D, Hermansson A, Hansson GK, Zhou X. Dendritic cells pulsed with malondialdehyde modified low density lipoprotein aggravate atherosclerosis in $\mathrm{ApoE}^{-/-}$mice. 
Atherosclerosis 2010; 209: 436-441.

11. Freigang S, Horkko S, Miller E, Witztum JL, Palinski W. Immunization of LDL receptor-deficient mice with homologous malondialdehyde-modified and native LDL reduces progression of atherosclerosis by mechanisms other than induction of high titers of antibodies to oxidative neoepitopes. Arterioscler Thromb Vasc Biol 1998; 18: 1972-1982.

12. Schiopu A, Bengtsson J, Soderberg I, Janciauskiene S, Lindgren $\mathrm{S}$, Ares MP, et al. Recombinant human antibodies against aldehyde-modified apolipoprotein B-100 peptide sequences inhibit atherosclerosis. Circulation 2004; 110: 2047-2052.

13. Binder CJ, Horkko S, Dewan A, Chang MK, Kieu EP, Goodyear $\mathrm{CS}$, et al. Pneumococcal vaccination decreases atherosclerotic lesion formation: Molecular mimicry between Streptococcus pneumoniae and oxidized LDL. Nat Med 2003; 9: 736-743.

14. Caligiuri G, Khallou-Laschet J, Vandaele M, Gaston AT, Delignat S, Mandet C, et al. Phosphorylcholine-targeting immunization reduces atherosclerosis. J Am Coll Cardiol 2007; 50: $540-546$

15. Yu K, Zhu P, Dong Q, Zhong Y, Zhu Z, Lin Y, et al. Thymic stromal lymphopoietin attenuates the development of atherosclerosis in ApoE $\mathrm{E}^{-/-}$mice. J Am Heart Assoc 2013; 2: e391.

16. Daugherty A, Whitman SC. Quantification of atherosclerosis in mice. Methods Mol Biol 2003; 209: 293-309.

17. Palinski W, Tangirala RK, Miller E, Young SG, Witztum JL. Increased autoantibody titers against epitopes of oxidized LDL in LDL receptor-deficient mice with increased atherosclerosis. Arterioscler Thromb Vasc Biol 1995; 15: 1569-1576.

18. Cybulsky MI, Cheong C, Robbins CS. Macrophages and dendritic cells: Partners in atherogenesis. Circ Res 2016; 118: $637-652$

19. Angeli V, Llodra J, Rong JX, Satoh K, Ishii S, Shimizu T, et al. Dyslipidemia associated with atherosclerotic disease systemically alters dendritic cell mobilization. Immunity 2004; 21: 561 574.

20. Miyashita K, Ohori J, Nagano H, Fukuyama S, Kurono Y. Intranasal immunization with phosphorylcholine suppresses allergic rhinitis in mice. Laryngoscope 2018; 128: E234-E240.

21. Fujimoto N, Ishida H, Nakamura I, Ogasawara K, Itoh Y. Quantities of interleukin-12p40 in mature CD8alpha negative dendritic cells correlate with strength of TCR signal and determine Th cell development. Microbiol Immunol 2003; 47: 1017-1024.
22. Shen H, Tesar BM, Walker WE, Goldstein DR. Dual signaling of MyD88 and TRIF is critical for maximal TLR4-induced dendritic cell maturation. J Immunol 2008; 181: 1849-1858.

23. Goodridge HS, McGuiness S, Houston KM, Egan CA, AlRiyami L, Alcocer MJ, et al. Phosphorylcholine mimics the effects of ES-62 on macrophages and dendritic cells. Parasite Immunol 2007; 29: 127-137.

24. Buono C, Pang H, Uchida Y, Libby P, Sharpe AH, Lichtman AH. B7-1/B7-2 costimulation regulates plaque antigen-specific $\mathrm{T}$-cell responses and atherogenesis in low-density lipoprotein receptor-deficient mice. Circulation 2004; 109: 2009-2015.

25. Fredrikson GN, Soderberg I, Lindholm M, Dimayuga P, Chyu KY, Shah PK, et al. Inhibition of atherosclerosis in apoE-null mice by immunization with apoB-100 peptide sequences. Arterioscler Thromb Vasc Biol 2003; 23: 879-884.

26. Wigren M, Bengtsson D, Duner P, Olofsson K, Bjorkbacka H, Bengtsson E, et al. Atheroprotective effects of alum are associated with capture of oxidized LDL antigens and activation of regulatory T cells. Circ Res 2009; 104: e62-e70.

27. Klingenberg R, Lebens M, Hermansson A, Fredrikson GN, Strodthoff D, Rudling M, et al. Intranasal immunization with an apolipoprotein B-100 fusion protein induces antigen-specific regulatory $\mathrm{T}$ cells and reduces atherosclerosis. Arterioscler Thromb Vasc Biol 2010; 30: 946-952.

28. Maron R, Sukhova G, Faria AM, Hoffmann E, Mach F, Libby $\mathrm{P}$, et al. Mucosal administration of heat shock protein-65 decreases atherosclerosis and inflammation in aortic arch of low-density lipoprotein receptor-deficient mice. Circulation 2002; 106: $1708-1715$.

29. van Puijvelde GH, Hauer AD, de Vos P, van den Heuvel R, van Herwijnen MJ, van der Zee R, et al. Induction of oral tolerance to oxidized low-density lipoprotein ameliorates atherosclerosis. Circulation 2006; 114: 1968-1976.

30. Habets KL, van Puijvelde GH, van Duivenvoorde LM, van Wanrooij EJ, de Vos P, Tervaert JW, et al. Vaccination using oxidized low-density lipoprotein-pulsed dendritic cells reduces atherosclerosis in LDL receptor-deficient mice. Cardiovasc Res 2010; 85: 622-630.

31. Hermansson A, Johansson DK, Ketelhuth DF, Andersson J, Zhou $\mathrm{X}$, Hansson GK. Immunotherapy with tolerogenic apolipoprotein B-100-loaded dendritic cells attenuates atherosclerosis in hypercholesterolemic mice. Circulation 2011; 123: 1083-1091. 